Mens

revue d'histoire intellectuelle de l'Amérique française

\title{
L'histoire des idées et de la culture au Québec (1760-2003) : Troisième supplément bibliographique (1998-2003)
}

\section{Yvan Lamonde et Éric Leroux}

Volume 6, numéro 1, automne 2005

URI : https://id.erudit.org/iderudit/1024267ar

DOI : https://doi.org/10.7202/1024267ar

Aller au sommaire du numéro

Éditeur(s)

Centre de recherche en civilisation canadienne-française

ISSN

1492-8647 (imprimé)

1927-9299 (numérique)

Découvrir la revue

Citer ce document

Lamonde, Y. \& Leroux, É. (2005). L'histoire des idées et de la culture au Québec

(1760-2003) : Troisième supplément bibliographique (1998-2003). Mens, 6(1),

159-160. https://doi.org/10.7202/1024267ar 
L'HISTOIRE DES IDÉES ET DE LA CULTURE AU QUÉBEC (1760-2003) : TROISIEME SUPPLÉMENT BIBLIOGRAPHIQUE (1998-2003)

\author{
Yvan Lamonde \\ Département de langue et littérature françaises \\ Université McGill
}

Éric Leroux École de bibliothéconomie et des sciences de l'information Université de Montréal

Mens - Revue d'bistoire intellectuelle de l'Amérique française est heureuse de présenter à ses lecteurs le troisième supplément à l'exhaustive bibliographie sur l'histoire des idées et de la culture au Québec compilée par le professeur Yvan Lamonde depuis 1989. Ce supplément bibliographique fait suite aux parutions suivantes:

Yvan Lamonde, L'bistoire des idées au Québec (1760-1960). Bibliographie des études, Montréal, Bibliothèque nationale du Québec, 1989, 167 p.

Yvan Lamonde, "L'histoire culturelle et intellectuelle du Québec (1960-1990) : bibliographie des études ", Littératures, $\mathrm{n}^{\circ} 4$ (1989), pp. 155-189. 
Yvan Lamonde, «L'histoire des idées au Québec (17601993). Premier supplément bibliographique et tendances de la recherche", Les Cabiers d'bistoire du Québec au $X X^{e}$ siècle. - Première partie, $\mathrm{n}^{\circ} 3$ (hiver 1995), pp. 163-176.

- Deuxième partie, $\mathrm{n}^{\circ} 4$ (été 1995), pp. 152-167.

Yvan Lamonde, "L'histoire des idées et de la culture au Québec (1760-1997) : deuxième supplément bibliographique (1993-1997) et tendances de la recherche», Bulletin d'bistoire politique. Disponible dans le site Internet du Bulletin d'histoire politique, à l'adresse suivante: http://www.unites.uqam.ca/bhp/biblio1.htm

Les lecteurs intéressés à consulter ce troisième supplément peuvent aller le télécharger dans le site Internet de Mens, www.hst.ulaval.ca/revuemens, rubrique "Bibliographies". Cette bibliographie est également disponible en brochure, qu'on peut consulter en bibliothèque ou encore commander dans le site Internet de la revue, rubrique "Commande de numéros à l'unité ».

Nous profitons de l'occasion pour annoncer que Mens prend le relais de $\mathrm{M}$. Lamonde et de ses collaborateurs pour la mise à jour de cette bibliographie. 